\title{
Erratum to: Psychology of Working Narratives of STEM Career Exploration for Non-Dominant Youth
}

\author{
Sheron L. Mark ${ }^{1}$
}

Published online: 8 November 2016

(C) Springer Science+Business Media New York 2016

Erratum to: J Sci Educ Technol

DOI: 10.1007/s10956-016-9646-0

The original version of this article unfortunately contained a mistake.

Acknowledgments should read:

This work is supported in part through the National Science Foundation's Information Technology Experiences for Students and Teachers (ITEST) program (Grants \#0525040 and \#0833624), a Hewlett Packard Foundation Teaching with Technology Program (Grant \#189660), the Peter J. Sharp Foundation, and the Lynch School of Education at Boston College. Any opinions, findings, and conclusions or recommendations expressed in this material are those of the author(s) and do not necessarily reflect the views of the National Science Foundation.

The online version of the original article can be found at http://dx.doi. org/10.1007/s10956-016-9646-0

Sheron L. Mark

sheron.mark@louisville.edu

1 Department of Middle and Secondary Education, College of

Education and Human Development, University of Louisville, 1905

S 1st Street, Louisville, KY 40292, USA 